\title{
Analyzing the returns to entrepreneurship by a modified Lazear model
}

\author{
Björn Hårsman (D) - Lars-Göran Mattsson $(\mathbb{D}$
}

Accepted: 2 July 2020 / Published online: 14 August 2020

(C) The Author(s) 2020

\begin{abstract}
A modified version of Lazear's model (in American Economic Review, 94, 208-211, 2004, Journal of Labor Economics, 23, 649-680, 2005) for occupational choice is formulated. It includes a utility adjustment factor that captures the combined effect of nonpecuniary benefits and uncertainty associated with entrepreneurship. We show that the counterfactual income returns to entrepreneurship are lower than the market value of entrepreneurial talent and higher than the inverse of the utility adjustment factor. Moreover, if the skill profiles in the population are Fréchet-distributed, the ratio between the expected incomes of entrepreneurs and observationally similar wage employees is lower than the inverse of the utility adjustment factor. Thus, entrepreneurs will on average earn less than wage employees if the utility adjustment factor is greater than or equal to one. It is also shown that the self-selection bias related to this income ratio or returns measure increases with the observed percentage of entrepreneurs. Swedish employment data are used to calibrate the modified Lazear model. The empirical results indicate that uncertainty considerations might be more important for the occupational choices than nonpecuniary benefits.
\end{abstract}

B. Hårsman $(\bowtie)$

Department of Industrial Economics and Management, KTH

Royal Institute of Technology, SE-100 44 Stockholm, Sweden e-mail: bjorn.harsman@indek.kth.se

L.-G. Mattsson

Department of Civil and Architectural Engineering, KTH Royal Institute of Technology, SE-100 44 Stockholm, Sweden e-mail: lgm@kth.se
Keywords Returns to entrepreneurship · Occupational choice $\cdot$ Nonpecuniary benefits $\cdot$ Self-employment $\cdot$ Selfselection · Fréchet distribution · Uncertainty $\cdot$ Risk

JEL codes M13 $\cdot \mathrm{J} 24 \cdot \mathrm{J} 3 \cdot \mathrm{L} 26$

\section{Introduction}

This paper analyzes the returns to entrepreneurship by applying a utility-based version of Lazear's (2002, 2004, 2005) occupational choice model. The modified model allows income uncertainty and nonpecuniary benefits associated with entrepreneurship to influence the occupational choice. In Lazear's original model, the individuals have two basic skills, and their choices between entrepreneurship and wage employment are determined by the resulting incomes. Individuals that choose wage employment will be paid according to the strength of their strongest skill, and the payment for those that choose entrepreneurship will equal the strength of their weakest skill times a positive parameter reflecting the market value of entrepreneurial talent. Income maximization implies that individuals having balanced skills are more likely than others to become entrepreneurs.

Different aspects of Lazear's model have been tested in a large number of empirical studies. Most of them seem to support the implication that entrepreneurs have more balanced skills than wage employees; see Lazear (2004, 2005), Wagner (2003, 2006), Cho and Orazem (2014), Bublitz and Noseleit (2014), Tegtmeier et al. 
(2016), Aldén et al. (2017) and Krieger et al. (2018), for instance. The model has also been criticized. A longstanding issue in the literature relates to the observation that entrepreneurs tend to earn less than comparable wage employees; see Hamilton (2000) and Åstebro (2012). Hamilton (2000) suggests that nonpecuniary benefits of being one's own boss might compensate for the observed earning differences. Hartog et al. (2010) claim that nonpecuniary benefits seem to be necessary to solve "the returns-to-entrepreneurship puzzle," and Benz (2009) states that "...entrepreneurship cannot possibly be understood as a quest for profit alone" (page 24).

The criticism seems to exclude an occupational choice model based on income maximization alone. However, it should be noted that Lazear (2002) shows that whether his model will result in higher or lower average income for entrepreneurs than for wage employees depends upon the assumption made about the distribution of skill profiles in the population. Using numerical methods, he shows that a normal distribution will always imply a higher average income for entrepreneurs than for wage employees, whereas a gamma distribution, under some conditions, will reverse that relationship. Applying another income maximization model, Jovanovic (2019) shows that whether the ratio of entrepreneurial income to wage income will exceed or fall below one depends upon the assumed values of model parameters such as liquidity constraints and the correlation between management and working skills.

Lazear's model has also been criticized for excluding the uncertainties and risks characterizing entrepreneurship. Modeling the occupational choice, Ekelund et al. (2005), Brown et al. (2011), and Hvide and Panos (2014), for instance, show that risk tolerance promotes entrepreneurship. Hsieh et al. (2017) include the acquisition of skills as a choice variable rather than being taken as given. Applying a two-stage model, they conclude that risk aversion might promote entrepreneurship, seemingly in contradiction to the previous studies.

Another common explanation for the observed earning differential between entrepreneurs and employees is related to the difficulty of measuring entrepreneurial earnings and to the definition of an entrepreneur; see Parker (2018) for an overview. Lechman (2015) reports that the contribution of different working conditions to the earning gap is marginal and concludes that income underreporting might play the main role. According to Berglann et al. (2011) and Åstebro and Chen (2014), entrepreneurs might in fact earn more than comparable wage employees provided that their incomes are measured accurately. Levine and Rubinstein (2016) differentiate between incorporated and unincorporated selfemployed and show that the incorporated self-employed earn more and the unincorporated less than comparable wage employees.

In addition to the measurement problem, selfselection makes it difficult to estimate what entrepreneurs would have earned if they instead had chosen to become employees. Hyytinen et al. (2013) correct for the heterogeneity caused by genetic factors by using a database for identical twins that includes information about earnings as well as working conditions. They report negative earning returns but compensating positive nonpecuniary benefits for entrepreneurs.

The basic aim of our paper is to provide a theoretical framework that can be used to analyze how occupational choices are affected by skill profiles, incomes, and the combined influence of nonpecuniary benefits and income uncertainty. We will assume that the occupational choice is determined by utility maximization rather than by income maximization as in Lazear's model. The utility of wage employment equals the received income as in Lazear's model. The utility of entrepreneurship, however, equals the income expected by the individual multiplied by a utility adjustment factor. This factor captures the combined effects of nonpecuniary benefits and the uncertainty about what the income actually will be. The utility mapping implies that if, for instance, a potential entrepreneur adjusts the utility upwards by $15 \%$ because of more autonomy and downwards by $5 \%$ because of income uncertainty, then the end result will be a utility adjustment factor of $1.093 .^{1,2}$ For this modified model, it is possible to show that the income returns to entrepreneurship - relative to the counterfactual incomes as wage employed - are greater than the inverse of the utility adjustment factor and lower than or equal to the market value of entrepreneurial talent.

In order to derive further theoretical implications of our modified model and to test it empirically, we will specify a statistical distribution of the skills in a

\footnotetext{
$\overline{{ }^{1} \text { Parker (2018) }}$ provides an overview of studies investigating the importance of nonpecuniary attributes of entrepreneurship.

${ }^{2}$ Block et al. (2015) report support for the hypothesis that the willingness to take risks is positively correlated with the nonmonetary benefits.
} 
population. Earlier empirical studies of income differences between entrepreneurs and wage employees provide some hints for this specification. First, the skill distribution should allow, but not require, lower average earnings of entrepreneurs than of observationally similar employees. It follows that neither a normal nor a uniform skill distribution would be appropriate, since both imply a reversed income ratio as shown by Lazear (2002) and Åstebro and Thompson (2011), respectively. Furthermore, the specification should be compatible with commonly observed differences between the income distribution of entrepreneurs and wage employees. As shown by Hamilton (2000) and Parker (2018), for instance, the income distribution of entrepreneurs typically has a larger variance and a larger positive skew. Another consistent feature is an overrepresentation of entrepreneurs in the lower and upper parts of the overall income distribution. By and large, similar differences hold for the Swedish income distribution data that we use to apply the model empirically. We have chosen the Fréchet distribution, which is positively skewed with a fat right-hand tail, since it fulfills both the stated condition and is compatible with the observed characteristics of the income distributions of entrepreneurs and work employees. ${ }^{3}$ It is also attractive because its properties make it possible to relate analytically the incomes of entrepreneurs and wage employees to their counterfactual incomes. This allows us to analyze the selfselection bias related to a commonly used measure of the income returns to entrepreneurship: the ratio between the average income for observationally similar entrepreneurs and wage employed. Furthermore, when the skills are Fréchet-distributed, the parameters of the model are straightforward to calibrate against commonly available labor market data.

The paper contributes to earlier studies in several ways. It shows that the combined influence of nonpecuniary benefits and uncertainty is crucial for the counterfactual income returns to entrepreneurship; the lower bound on this returns measure equals the inverse of the utility adjustment factor. If we add the assumption

\footnotetext{
${ }^{3}$ The Fréchet distribution is one of three univariate extreme value distributions that also include the Gumbel and Weibull distributions; see Kotz and Nadarajah (2000), for instance.
}

that skills are Fréchet-distributed, entrepreneurs will on average earn less than comparable wage employees provided that the adjustment factor is greater than or equal to one. Another conclusion is that the selfselection bias of this income ratio when used as a returns measure will be larger, the higher the relative frequency of entrepreneurs.

We use Swedish employment register data to calibrate and apply the model for two university-educated population groups: architects and electrical engineers. Entrepreneurs are defined as self-employed and we make a distinction between all self-employed and the subset that are employers. The calibrated parameters show that the corresponding entrepreneurial supply curves differ considerably and that the utility adjustment factor is less than one for three out of four analyzed subgroups.

The paper is organized as follows. Section 2 formulates the model framework and its theoretical implications. Section 3 presents our data and Section 4 presents the calculated values of the counterfactual income returns and the model parameters. Section 4 also includes a comparison between the theoretically derived income distributions based on the calibrated parameters and the actual income distributions in our data. Concluding remarks follow in Section 5. Mathematical proofs and the applied procedure for parameter calibration are in Appendix 1 and additional data in Appendix 2.

\section{The model framework}

Following Lazear (2005), we consider a population of individuals who choose between becoming entrepreneurs or wage employees. Each individual has two basic skills with strengths that vary in the population according to the positive random variables $X_{1}$ and $X_{2}$. The income as an entrepreneur is determined by the individual's weakest skill times a positive parameter $\lambda$ representing the market value of entrepreneurial talent. For a randomly selected individual, the entrepreneurial income is thus $\lambda \cdot \min \left\{X_{1}, X_{2}\right\}$. As a wage employee, on the other hand, the income will correspond to the strength of the individual's strongest skill, that is, $\max \{$ $\left.X_{1}, X_{2}\right\}$.

As discussed in the introduction, nonpecuniary benefits may explain why some individuals become entrepreneurs although their incomes as wage employees 
would be higher. ${ }^{4}$ On the other hand, uncertainty about the income as an entrepreneur may explain why some individuals choose to become wage employees although their entrepreneurial incomes would be higher. To allow for nonpecuniary benefits and income uncertainty for entrepreneurs, we make a slight modification of Lazear's occupational choice model. Instead of assuming that the entrepreneurial income is certain, we assume that it is uncertain with expected value $\lambda \cdot \min \left\{x_{1}, x_{2}\right\}$ for an individual with observed skill strengths of $x_{1}$ and $x_{2}$. Because of the uncertainty, the utility of the income is presumably reduced when compared with an equally large certain income. Nonpecuniary benefits may also influence the utility of entrepreneurship in relation to the expected income. We assume that these effects can be combined in a common positive utility adjustment factor $s$ such that the utility of entrepreneurship for a randomly selected individual is ${ }^{5}$

$U_{\mathrm{E}}=s \cdot \lambda \cdot \min \left\{X_{1}, X_{2}\right\}$.

Simplicity is the main reason for assuming a multiplicative adjustment. Considering nonpecuniary benefits, it seems reasonable to assume that the benefits of autonomy or from a "taste for variety" will increase with the income as is argued by Benz (2009). ${ }^{6}$ A proportional adjustment for income uncertainty is perhaps more questionable but seems to be in accordance with experimental studies showing that individuals tend to simplify their approach when choosing between certain and uncertain outcomes; see Kahneman and Tversky (1979). Thus, the $s$ parameter reflects the behavior of a person who first adjusts his expected income because of perceived nonmonetary benefits and then adjusts it because of income uncertainty. For wage employees, we keep Lazear's assumption that the utility equals the income

$U_{\mathrm{W}}=\max \left\{X_{1}, X_{2}\right\}$.

\footnotetext{
$\overline{{ }^{4} \text { The possibility }}$ to pursue one's own ideas, broader skill utilization, and richer work content are examples of nonpecuniary benefits. Aspects of this kind are sometimes interpreted in terms of procedural utility; see Frey et al. (2004), for instance.

${ }^{5}$ A natural extension of this approach would be to treat the market value of entrepreneurial talent $\lambda$ and the utility adjustment factor $s$ as stochastic. This is beyond the scope of the present study, however.

${ }^{6}$ Benz (2009) assumes that $U_{\mathrm{E}}=(\lambda+\eta) \cdot \min \left\{X_{1}, X_{2}\right\}$, where the deterministic factor $\eta>1-\lambda$ accounts for nonmonetary benefits. Our approach is mathematically equivalent to his, since $\lambda+\eta=s \cdot \lambda$ for $s=\eta / \lambda+1$.
}

With this slight modification of Lazear's model, an individual chooses entrepreneurship if and only if it gives a higher utility:

$U_{\mathrm{E}}>U_{\mathrm{W}}$.

We note that this could only happen if $s \cdot \lambda>1$, which is therefore assumed. If this condition is not fulfilled, no one would choose to be an entrepreneur. The probability that a randomly drawn individual chooses entrepreneurship is then

$\begin{aligned} p_{\mathrm{E}} & =\operatorname{Pr}\left[U_{\mathrm{E}}>U_{\mathrm{W}}\right]=\operatorname{Pr}\left[s \cdot \lambda \cdot \min \left\{X_{1}, X_{2}\right\}>\max \left\{X_{1}, X_{2}\right\}\right] \\ & =\operatorname{Pr}\left[s \cdot \lambda \cdot X_{1}>X_{2}>X_{1}\right]+\operatorname{Pr}\left[s \cdot \lambda \cdot X_{2}>X_{1}>X_{2}\right] .\end{aligned}$

The probability $p_{\mathrm{E}}$ obviously increases with both $s$ and $\lambda$.

The logic of the occupational choice model is illustrated in Fig. 1. The probability of becoming an entrepreneur $p_{\mathrm{E}}$ is equal to the probability that the random vector $\left(X_{1}, X_{2}\right)$ falls between the two rays $X_{2}=s \cdot \lambda \cdot X_{1}$ and $X_{2}=X_{1} /(s \cdot \lambda)$. Clearly, $p_{\mathrm{E}}$ goes from zero to one as $s \cdot \lambda$ goes from one to infinity, since then the rays will shift from coinciding with the diagonal to coinciding with the axes.

Next we let $Y_{\mathrm{E}}$ and $Y_{\mathrm{W}}$ denote the income earned by (self-selected) entrepreneurs and (self-selected) wage employees, respectively. Formally,

$Y_{\mathrm{E}}=\lambda \cdot\left[\min \left\{X_{1}, X_{2}\right\} \mid s \cdot \lambda \cdot \min \left\{X_{1}, X_{2}\right\}>\max \left\{X_{1}, X_{2}\right\}\right]$, and

$Y_{\mathrm{W}}=\left[\max \left\{X_{1}, X_{2}\right\} \mid s \cdot \lambda \cdot \min \left\{X_{1}, X_{2}\right\} \leq \max \left\{X_{1}, X_{2}\right\}\right]$.

By definition, each individual chooses occupational status to maximize his utility. Does this mean that he also maximizes his income? This is only true if there are no other factors than income that determines the utility, that is, if $s=1$. To analyze the general case with a utility adjustment factor $s$ that is not necessarily equal to one, we first define the counterfactual income of an entrepreneur as the income he would have earned, if he instead had chosen to become a wage employee

$Z_{\mathrm{E}}=\left[\max \left\{X_{1}, X_{2}\right\} \mid s \cdot \lambda \cdot \min \left\{X_{1}, X_{2}\right\}>\max \left\{X_{1}, X_{2}\right\}\right]$

and the corresponding counterfactual income of a wage employee as the income he would have earned, if he instead had chosen to become an entrepreneur

$Z_{W}=\lambda \cdot\left[\min \left\{X_{1}, X_{2}\right\} \mid s \cdot \lambda \cdot \min \left\{X_{1}, X_{2}\right\} \leq \max \left\{X_{1}, X_{2}\right\}\right]$. 
Fig. 1 Self-selection into entrepreneurship or wage employment by individuals endowed with skills $X_{1}$ and $X_{2}$ and with a utility adjustment factor $s$ and a market value of entrepreneurship $\lambda$ such that $s \cdot \lambda>1$. Adapted from Lazear (2005)

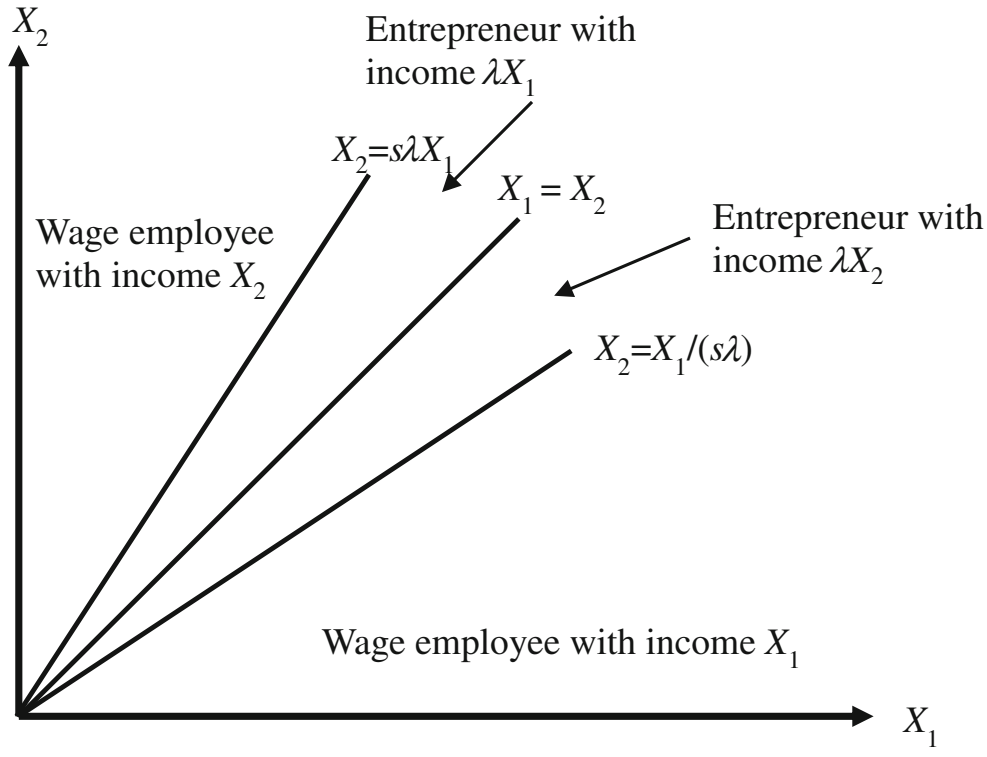

Consider now an individual's income returns to entrepreneurship and to wage employment relative to the counterfactual incomes, that is, $Y_{\mathrm{E}} / Z_{\mathrm{E}}$ and $Y_{\mathrm{W}} / Z_{\mathrm{W}}$, respectively. It should be noted that by construction, these counterfactual income returns are unbiased by selfselection.

Moreover, upper and lower bounds on these income returns are easily derived. For an entrepreneur with perfectly balanced skills, that is, for whom $X_{1}=X_{2}$, the relative income returns are $Y_{\mathrm{E}} / Z_{\mathrm{E}}=\lambda$, since $\min \left\{X_{1}\right.$, $\left.X_{2}\right\}=\max \left\{X_{1}, X_{2}\right\}$. For an entrepreneur who is indifferent between being an entrepreneur or a wage employee, that is, for whom $s \cdot \lambda \cdot \min \left\{X_{1}, X_{2}\right\}=\max \left\{X_{1}, X_{2}\right\}$, the counterfactual income returns are $Y_{\mathrm{E}} / Z_{\mathrm{E}}=\lambda \cdot \min \{$ $\left.X_{1}, X_{2}\right\} / \max \left\{X_{1}, X_{2}\right\}=1 / s$. Hence

$1 / s<Y_{\mathrm{E}} / Z_{\mathrm{E}} \leq \lambda$.

Similarly, for an employee who is indifferent between being a wage employee or an entrepreneur, that is, for whom $s \cdot \lambda \cdot \min \left\{X_{1}, X_{2}\right\}=\max \left\{X_{1}, X_{2}\right\}$, the relative income returns are $Y_{\mathrm{W}} / Z_{\mathrm{W}}=\max \left\{X_{1}, X_{2}\right\} / \lambda$. $\min \left\{X_{1}, X_{2}\right\}=s$. Hence

$Y_{\mathrm{W}} / Z_{\mathrm{W}} \geq s$.

Based on these concepts of individual counterfactual income returns, we define the counterfactual income returns to entrepreneurship as

$\mu_{\mathrm{E}}=E\left[Y_{\mathrm{E}}\right] / E\left[Z_{\mathrm{E}}\right]$, and the counterfactual income returns to wage employment as

$\mu_{\mathrm{W}}=E\left[Y_{\mathrm{W}}\right] / E\left[Z_{\mathrm{W}}\right]$

Before introducing a specific skill distribution, we just assume that the two random skills $X_{1}$ and $X_{2}$ are statistically independent and identically distributed with strictly positive densities on the positive axes and having finite expected values. Then obviously the same inequalities hold for the returns based on expected incomes. In fact, the non-strict inequalities are then strengthened to strict ones, since the skill distributions have been assumed to have strictly positive densities. We have therefore established the following proposition:

Proposition 1 Consider our modified Lazear model with $s \cdot \lambda>1$ and with random skill profiles $X_{1}>0$ and $X_{2}>0$ that are statistically independent and identically distributed with strictly positive densities on the positive axes and with finite expected values. The counterfactual income returns to entrepreneurship $\mu_{E}$ then satisfy

$1 / s<\mu_{E}<\lambda$,

\footnotetext{
${ }^{7}$ These counterfactual income returns measures were introduced in Hårsman et al. (2018) for a utility adjustment factor $s=1$. Alternative measures could be defined as $\widetilde{\mu}_{\mathrm{E}}=E\left[Y_{\mathrm{E}} / Z_{\mathrm{E}}\right]$ and $\widetilde{\mu}_{\mathrm{W}}=$ $E\left[Y_{\mathrm{W}} / Z_{\mathrm{W}}\right]$. For Fréchet-distributed skills, the differences between the two kinds of measures are small. In addition, the proposed measures $\mu_{\mathrm{E}}$ and $\mu_{\mathrm{W}}$ are easier to apply mathematically.
} 
and the counterfactual income returns to wage employment satisfy

$\mu_{W}>s$.

It should be noted that the inequalities hold for any continuous skill distribution specified as in the proposition. As we will see in the empirical application reported in Table $2, \mu_{\mathrm{E}}$ will be very close to the average of its boundaries, that is, $\mu_{\mathrm{E}} \approx(\lambda+1 / s) / 2$.

If the utility adjustment factor $s \leq 1$, the first inequality guarantees that entrepreneurs on average will earn more than they would do as wage employees. If, on the other hand, $s>1$, then the reversed relationship is not excluded. In either case, their expected income returns will be smaller than the market value of entrepreneurship talent, that is, $\mu_{E}<\lambda$. The second inequality says that wage employees on average will earn more than they would do as entrepreneurs, if the utility adjustment factor $s \geq 1$. They could, on the other hand, on average earn less than they would do as entrepreneurs if $s<1$, and hence, $\mu_{\mathrm{W}}$ might then be less than one. Finally, if $s=1$, both entrepreneurs and wage employees will on average earn more than they would do by making the opposite occupational choice.

To be able to analyze the properties of our modified model further and to apply it to empirical data, we need to specify a distribution for the skills in the population. As already motivated, we will apply the Fréchet distribution. We first derive closed-form expressions for the occupational choice probabilities given Fréchet-distributed skills.

Proposition 2 Consider our modified Lazear model with $s \cdot \lambda>1$ and with random skills $X_{1}$ and $X_{2}$ that are statistically independent and identically $\operatorname{Fréchet}(\beta, v)$ distributed with $\beta>1$ and $v>0 .{ }^{8}$ The probability of entrepreneurship and wage employment are then, respectively,

$p_{E}=\frac{(s \lambda)^{\beta}-1}{(s \lambda)^{\beta}+1}$,

\footnotetext{
${ }^{8}$ A positive random variable is Fréchet $(\beta, v)$-distributed with shape parameter $\beta>0$ and scale parameter $v>0$, if its c.d.f. is $F(x)=e^{-(v / x)^{\beta}}, x>0$. For the expected value to exist, it is required that $\beta>1$, in which case it is $v \cdot \Gamma(1-1 / \beta)$, where the gamma function is defined by $\Gamma(x)=\int_{0}^{\infty} t^{x-1} e^{-t} d t$ for $x>0$. Some basic properties of the Fréchet distribution are stated in Appendix 1. These properties form the basis for its mathematical tractability.
}

and

$p_{W}=1-p_{E}=\frac{2}{(s \lambda)^{\beta}+1}$.

Proof See Appendix 1.

As expected, the supply of entrepreneurs $p_{\mathrm{E}}$ increases at a decreasing rate with increasing utility adjustment factor $s$ and increasing market value of entrepreneurial talent $\lambda$. The same holds for $p_{\mathrm{E}}$ vis-à-vis $\beta$. The latter conclusion is intuitively clear, since the larger the value of $\beta$, the smaller is the variance of the skill distributions (see Appendix 1), which in turn implies that the skills will be more balanced. ${ }^{9}$

With the same distributional assumptions, one can also derive closed-form expressions for the expected incomes of entrepreneurs and wage employees.

Proposition 3 Consider our modified Lazear model with the same assumptions as in Proposition 2. Then the expected incomes of entrepreneurs and wage employees are, respectively,

$\mathrm{E}\left[Y_{\mathrm{E}}\right]=\frac{1}{s} \cdot \frac{2(s \lambda)^{\beta} \cdot\left(1+(s \lambda)^{\beta}\right)^{1 / \beta}-2^{1 / \beta} s \lambda \cdot\left(1+(s \lambda)^{\beta}\right)}{(s \lambda)^{\beta}-1} \cdot v \cdot \Gamma(1-1 / \beta)$ and

$$
\mathrm{E}\left[Y_{\mathrm{W}}\right]=\left(1+(s \lambda)^{\beta}\right)^{1 / \beta} \cdot v \cdot \Gamma(1-1 / \beta)
$$

Proof See Appendix 1.

The expected income of wage employees $E\left[Y_{\mathrm{W}}\right]$ obviously increases with both $\lambda$ and $s$ for given parameters $\beta$ and $v$. The explanation is that the strongest skill of those wage employees that then shift to entrepreneurs is likely to be relatively weak compared with the strongest skill of those that remain wage employed. It also seems intuitively reasonable that the expected income of entrepreneurs $E\left[Y_{\mathrm{E}}\right]$ should increase with $\lambda$ and decrease with $s$. This conjecture is supported by numerical experiments for relevant values of $\lambda, s$, and $\beta$. Moreover, suppose that the demand for entrepreneurs increases for given values of $s$ and $\beta$. In a balanced labor market, $\lambda$ then has to increase, which will increase the supply of entrepreneurs by an upward adjustment of their relative incomes. Again numerical experiments

\footnotetext{
${ }^{9}$ One may introduce positive statistical dependence between the skill variables $X_{1}$ and $X_{2}$ as shown in footnote 21 . The probability of entrepreneurship then goes to one, as these variables approach perfect correlation; see footnote 22 .
} 
for relevant parameter values indicate that $E\left[Y_{\mathrm{E}}\right] / E$ $\left[Y_{\mathrm{W}}\right]$ then increases, and hence, $E\left[Y_{\mathrm{E}}\right]$ increases relatively more than $E\left[Y_{\mathrm{W}}\right]$. If we assume that the demand for entrepreneurs is fixed, then the product $s \cdot \lambda$ has to be constant by Proposition 2. It follows that if the utility adjustment factor, that is $s$, increases, then the expected income of entrepreneurs decreases, while that of wage employees remains constant.

We are now in a position to establish a fundamental inequality for the ratio of the expected incomes of entrepreneurs to wage employees.

Proposition 4 Consider our modified Lazear model with the same assumptions as in Proposition 2. Then the ratio of the expected incomes of entrepreneurs to wage employees is

$E\left[Y_{\mathrm{E}}\right] / E\left[Y_{\mathrm{W}}\right]<1 / s$.

\section{Proof See Appendix 1.}

Although Fréchet-distributed skills are sufficient for this inequality to hold, it also holds for other skill distributions with a similar form. Lazear (2002) reports (for the case $s=1$ ) that the inequality is valid for gamma-distributed skills for sufficiently low values of $\lambda>1$. We have found that it also holds for Weibulldistributed skills under similar conditions. ${ }^{10}$

The proposition says that entrepreneurs on average will earn less than wage employees as long as entrepreneurship is associated with a utility adjustment factor greater than or equal to one, that is, if $s \geq 1$. However, if this is not the case, that is, if $0<s<1$, entrepreneurs may on average earn more than wage employees.

Suppose income is the only factor that determines the entrepreneurship utility, that is, $s=1$. Then entrepreneurs as well as wage employees will on average earn more than they would do by making the opposite occupational choice; $\mu_{\mathrm{E}}>1$ and $\mu_{\mathrm{W}}>1$. By Proposition 4 , this is fully consistent with entrepreneurs on average earning less than observationally similar wage

\footnotetext{
${ }^{10}$ With Weibull-distributed skills, it is possible to derive closed-form expressions for the income distributions for entrepreneurs and wage employees as well as their expected incomes. Preliminary analysis for $s=1$ indicates that the expected income of entrepreneurs is smaller or larger than that of wage employees depending on whether the market value of entrepreneurial talent $\lambda$ is smaller or larger than some critical value $\bar{\lambda}$. This critical value decreases as the shape parameter $\beta$ of the Weibull distribution increases.
}

employees. In this sense, there is no return-toentrepreneurship puzzle.

Self-selection bias is a recurrent problem in empirical studies using the ratio of expected entrepreneurial income to expected income of wage employed $E\left[Y_{\mathrm{E}}\right] / E$ $\left[Y_{\mathrm{W}}\right]$ as a measure of returns to entrepreneurship. ${ }^{11}$ That this measure underestimates the returns to entrepreneurship is clear since $E\left[Y_{\mathrm{E}}\right] / E\left[Y_{\mathrm{W}}\right]<\mu_{\mathrm{E}}$, which follows by combining Propositions 1 and 4 . We define the relative self-selection bias of the expected income ratio as

$b=\left[\mu_{\mathrm{E}}-E\left[Y_{\mathrm{E}}\right] / E\left[Y_{\mathrm{W}}\right]\right] / \mu_{\mathrm{E}}=1-E\left[Z_{\mathrm{E}}\right] / E\left[Y_{\mathrm{W}}\right] \in(0,1)$.

Next we show that the larger the fraction of entrepreneurs, the larger is the self-selection bias $b$.

Proposition 5 Consider our modified Lazear model with the same assumptions as in Proposition 2. Then the self-selection bias $b$, as a function of the probability of entrepreneurship $p_{E}$, is

$b\left(p_{E}\right)=\frac{1-\left(1-p_{E}\right)^{1 / \beta}}{p_{E}}$,

with $b$ strictly increasing from $1 / \beta$ to 1 as $p_{\mathrm{E}}$ increases from 0 to 1 and $b$ strictly decreasing in $\beta>1$.

Proof See Appendix 1.

\section{The data}

Our database-provided by Statistics Swedencomprises individual time series data of all employed individuals in Sweden from 2004 to 2008. Anyone working at least $1 \mathrm{~h}$ per week in November each year, 4.4 million individuals in 2008, is considered employed the same year, implying that both full-time and part-time employees are included. Each individual is categorized as either wage employed or self-employed. ${ }^{12}$ Individuals that combine wage employment and selfemployment are classified as wage employees if their income from wage employment is larger than the income from self-employment and vice versa. Since

\footnotetext{
11 Jovanovic (2019), for instance, uses the ratio of average incomes to analyze the entrepreneurship premium.

${ }^{12}$ All self-employed are owners of a registered incorporated or unincorporated business.
} 
combinations are rather common, it should be noted that even a small income change between the years might result in a reclassification of an individual from, say, self-employed to wage employed.

The income information corresponds to before-tax wage per year for wage employed and before-tax net business income per year for self-employed. Statistics Sweden multiplies reported business incomes by 1.6 in order to adjust for an observed tendency by business owners to report too low incomes. The incomes for those combining wage employment and selfemployment include both types of incomes. It follows that the income of self-employed combiners used in our analysis will be higher than their actual business income. The income of wage employed combiners will be higher or lower than their actual wage income depending on if their business income is positive or negative.

Since the purpose is to illustrate some empirical implications of our model specification, the calculations will be limited to the latest year 2008 and two populations of working individuals. We have chosen individuals that have the same length but different types of formal education and that differ significantly regarding the propensity to be self-employed: electrical engineers and architects that have a master's degree from a technical university. ${ }^{13}$ According to our model, the much higher self-employment rate among architects is related to the balance of skills, the utility adjustment factor, and the market value of entrepreneurship. Assuming that analytical and creative skills are important for the occupational choice, a seemingly reasonable hypothesis is that architects have a more balanced skill profile than electrical engineers.

Furthermore, we distinguish between all selfemployed and the subset of self-employed that hires at least one person, the latter to be denoted $1+$. The reason for this is that self-employed who work on their own account usually earn less than those who employ other persons; see Parker (2018), for instance.

Table 1 shows the average self-employment rates and the ratios of the average incomes of self-employed to wage employed in 2008. As indicated in Appendix 2, Table 4 , the variation in these values across the years 2004-2008 is relatively small.

\footnotetext{
${ }^{13}$ The corresponding populations of working individuals in the year 2008 are as follows: 13,088 and 4944, respectively (see Appendix 2, Table 4).
}

As already noted, the self-employment rates are much lower for electrical engineers than for architects: 9.3 as compared with $26.0 \%$. The corresponding percentages of self-employed hiring at least one person are about half as high. ${ }^{14}$

Only the self-employed architects that hire at least one person earn more than the wage employed. As expected, the income ratios are higher for the selfemployed that are employers than for all selfemployed. ${ }^{15}$ Our model provides some information about possible reasons for the latter differences. Since $E\left[Y_{\mathrm{E}}\right] / E\left[Y_{\mathrm{W}}\right]<1 / s$ by Proposition 4 , and $s$ is the utility adjustment factor, one explanation might be that the self-employed hiring others regard income uncertainty as more important, and positive benefits like being one's own boss as less important than the own-account selfemployed.

Table 5 in Appendix 2 provides additional information about the observed income percentiles in 2008. The 5 th income percentile is throughout lower for selfemployed than for wage employed. The pattern is less clear in the upper end of the income distribution.

Among the electrical engineers, the 95th and the 99th income percentiles are lower for self-employed than for wage employed. This holds for both categories of selfemployed. With one exception, the opposite relationship applies for the architects. The exception is the 95th income percentile for all self-employed architects. The overrepresentation of self-employed architects in both ends of the common income distribution is consistent with the characterization of entrepreneurs as "stars and misfits"; see Åstebro et al. (2011), for instance.

\section{Results}

The parameters of our modified Lazear model have been calibrated against the information about occupational status in Table 1 and average incomes and income percentiles in Tables 4 and 5 in Appendix 2 for the year $2008{ }^{16}$ Table 2 shows the calculated values of the counterfactual income returns and the calibrated model parameters.

\footnotetext{
${ }^{14}$ The upper part of the table compares all self-employed with all employed and the lower part the subset of self-employed hiring at least one person with all employed except the own account self-employed.

${ }^{15}$ See Parker (2018) and Dvouletý el al. (2019), for instance.

${ }^{16}$ See Appendix 1 for a description of the calibration procedure.
} 
Table 1 Percentage self-employed and the ratio of average income of self-employed to wage employed by education for the year 2008

\begin{tabular}{llc}
\hline Variable & Electrical engineers & Architects \\
\hline Percentage self-employed: all & 9.3 & 26.0 \\
Income ratio & 0.64 & 0.77 \\
Percentage self-employed: $1+$ & 4.3 & 14.2 \\
Income ratio & 0.79 & 1.02 \\
\hline
\end{tabular}

The counterfactual income returns to selfemployment as well as to wage employment are positive among all subgroups but "all self-employed electrical engineers"- their returns being $2 \%$ lower than if they had instead chosen wage employment. Furthermore, the table shows that the self-employment returns are higher for architects than for electrical engineers and for hiring self-employed as compared with all self-employed. The hypothesis, suggested by Proposition 1, that the counterfactual income returns to entrepreneurship $\mu_{\mathrm{E}}$ should be very close to the averages of the corresponding values of $\lambda$ and $1 / s$, is empirically verified. A comparison with Table 1 also confirms empirically the earlier theoretical result that the counterfactual income returns are higher than the corresponding income ratios.

Somewhat surprisingly, Table 2 also shows that the only category that has a utility adjustment factor $s$ exceeding one is "all self-employed electrical engineers." One obvious interpretation is that the trade-off between the hazards of entrepreneurship and the safety of wage employment has a stronger influence than nonpecuniary benefits among the other three categories.

As follows by Proposition 2, the probability of entrepreneurship will increase with the product of the two parameters $s$ and $\lambda$ as well as with $\beta$. Table 2 shows that the products are higher among architects than electrical engineers and also among all self-employed than self-employed hiring at least one person. Since the values of $\beta$ are lower among the architects, and lower values are associated with a larger variance (see Appendix 1), we can reject the hypothesis that architects have more balanced skill profiles than electrical engineers. Their much higher rate of self-employment is rather explained by a higher market value of entrepreneurial talent. However, our assumption about independent skills is an important caveat. As shown by Lazear
(2005), the supply of entrepreneurs will increase with the correlation between the two skills. Thus, the higher market value of entrepreneurial talent among architects than engineers might be explained by a lower skill correlation. If the assumption about uncorrelated skill distributions is relaxed, it also seems likely that the calibrated parameter values would change (see footnotes 21 and 22 for further information). Apart from our model, it is also possible that students interested in becoming entrepreneurs prefer to study architecture rather than engineering, or simply that it is more difficult for architects than for electrical engineers to find a well-paid employment matching their education. $^{17}$

According to Lazear (2005), the market value of entrepreneurial talent $\lambda$ adapts to ensure that the supply of entrepreneurs satisfies an exogenously given demand. The relationship between the entrepreneurship rates and $\lambda$ can therefore be summarized as an entrepreneurial supply curve. ${ }^{18}$ Using the calibrated parameter values given in Table 2, Fig. 2 illustrates the supply curves for the different categories. As expected, a higher market value of entrepreneurship increases the supply of self-employed. However, the supply consequences of the utility adjustment factor $s$ are more striking. The intercepts of the supply curves are equal to the inverse of the corresponding $s$ values. Since the latter value is lower among each category of architects than among the corresponding category of electrical engineers, it follows that the architects' supply curves start at a higher level.

As we clarify in Section 2, the income ratios presented in Table 1, interpreted as income returns to entrepreneurship, are biased by self-selection. A comparison with the counterfactual income returns in Table 2 indicates that the income ratio underestimates the "true" income returns for the category "all self-employed" by $35 \%$ for electrical engineers and $41 \%$ for architects. As explained in Proposition 5, the larger self-selection bias for architects results from their higher rate of selfemployment, since the $\beta$ values are rather similar.

\footnotetext{
${ }^{17}$ Appendix 2, Table 4, provides additional information about the income differences between architects and electrical engineers.

${ }^{18}$ The entrepreneurship probability in Proposition 2 implies $\lambda=\frac{1}{s} \cdot\left(\frac{1+p_{\mathrm{E}}}{1-p_{\mathrm{E}}}\right)^{1 / \beta}$.
} 
Table 2 Counterfactual income returns to entrepreneurship $\mu_{\mathrm{E}}$ and to wage employment $\mu_{\mathrm{W}}$ and calibrated utility adjustment factor $s$, market value of entrepreneurial talent $\lambda$, shape parameter $\beta$, and scale parameter $v$ (in thousand SEK per year) by education

\begin{tabular}{llll}
\hline Category & $\begin{array}{l}\text { Parameter/ } \\
\text { variable }\end{array}$ & $\begin{array}{l}\text { Electrical } \\
\text { engineers }\end{array}$ & Architects \\
\hline $\begin{array}{c}\text { All self-employed vs. all } \\
\text { wage employed }\end{array}$ & $\mu_{\mathrm{E}}$ & 0.98 & 1.30 \\
& $\mu_{\mathrm{W}}$ & 1.78 & 1.48 \\
& $s$ & 1.05 & 0.85 \\
& $\lambda$ & 1.01 & 1.43 \\
All self-employed hiring at & $\mu_{\mathrm{E}}$ & 2.95 & 2.70 \\
least one person (1+) vs. & $\mu_{\mathrm{W}}$ & 1.44 & 183 \\
all wage employed & $s$ & 0.85 & 1.11 \\
& $\lambda$ & 1.21 & 0.65 \\
& $\lambda$ & 2.99 & 2.85 \\
& $\beta$ & 332 & 202 \\
\hline
\end{tabular}

Proposition 3 in Appendix 1 shows how the income distributions for wage employed and entrepreneurs can be calculated. Using the parameter values reported in Table 2, we have computed the 5th, 25th, 50th, 75th, and 95th income percentiles and compared them with the corresponding observed income percentiles according to Appendix 2, Table 5. Table 3 reports the ratio of the computed to the observed income percentiles. Excluding the 5 th percentile, the fit is fairly good. It is somewhat better for self-employed hiring others than for all self-employed as well as for wage employees.

It is impossible to assess to what extent the reported differences depend upon the applied model, the Fréchet assumption, or the data. We think, however, that the fit is good enough to warrant further investigations. One obvious improvement would be to control for observable individual characteristics like age, gender, and labor market region. ${ }^{19}$

\section{Summary and concluding remarks}

The paper presents a modified version of Lazear's model of selection into entrepreneurship. The modification means that the expected entrepreneurial incomes, as perceived by the individuals, are multiplied with a utility

\footnotetext{
${ }^{19}$ Hårsman et al (2018) provide an example for the case $s=1$.
}

adjustment factor assumed to handle the combined influence of nonpecuniary benefits and the income uncertainty related to entrepreneurship. In the theoretical part of the paper, we show that the counterfactual income returns to entrepreneurship are greater than the inverse of the utility adjustment factor and lower than the market value of entrepreneurial talent. Adding the assumption that the skill profiles in a population are Fréchetdistributed, utility maximization will lead to lower expected earnings for entrepreneurs than for wage employees, if the utility adjustment factor $s$ is greater than or equal to one. Hence, Lazear's model (having $s=1$ ) is fully compatible with lower average earnings for entrepreneurs than for observationally similar wage employed. Furthermore, we show that the selfselection bias of the ratio of the average incomes of entrepreneurs to observationally similar wage employees, when used as a measure of income returns to entrepreneurship, increases with the observed percentages of entrepreneurs.

Data from the Swedish employment register for the year 2008 are used to calibrate the model parameters for two university-educated population groups: architects and electrical engineers. As shown theoretically and confirmed empirically, the counterfactual income returns to self-employment are higher than the returns indicated by the income ratio between observationally similar self-employed and wage employed. Moreover, the entrepreneurial supply curves differ substantially between the two population groups and within the groups between all selfemployed and those hiring at least one person. The calibrated parameters indicate that nonpecuniary benefits as well as risk considerations should be included in occupational choice models. Our assumption that the skills are Fréchet-distributed gains circumstantial support from a comparison of the observed and the computed model-based income distributions. It also gains some indirect support, since it allows, but does not require, the average income of self-employed to be lower than that of wage employed.

Some of our simplifying model assumptions should be emphasized. We assume that architects and electrical engineers need the same number and type of skills whether wage employees or entrepreneurs and that the two skill distributions are independent. These assumptions are bound to influence our results since the supply of entrepreneurs would be smaller if more than two skills are needed and larger if the distributions of skills 


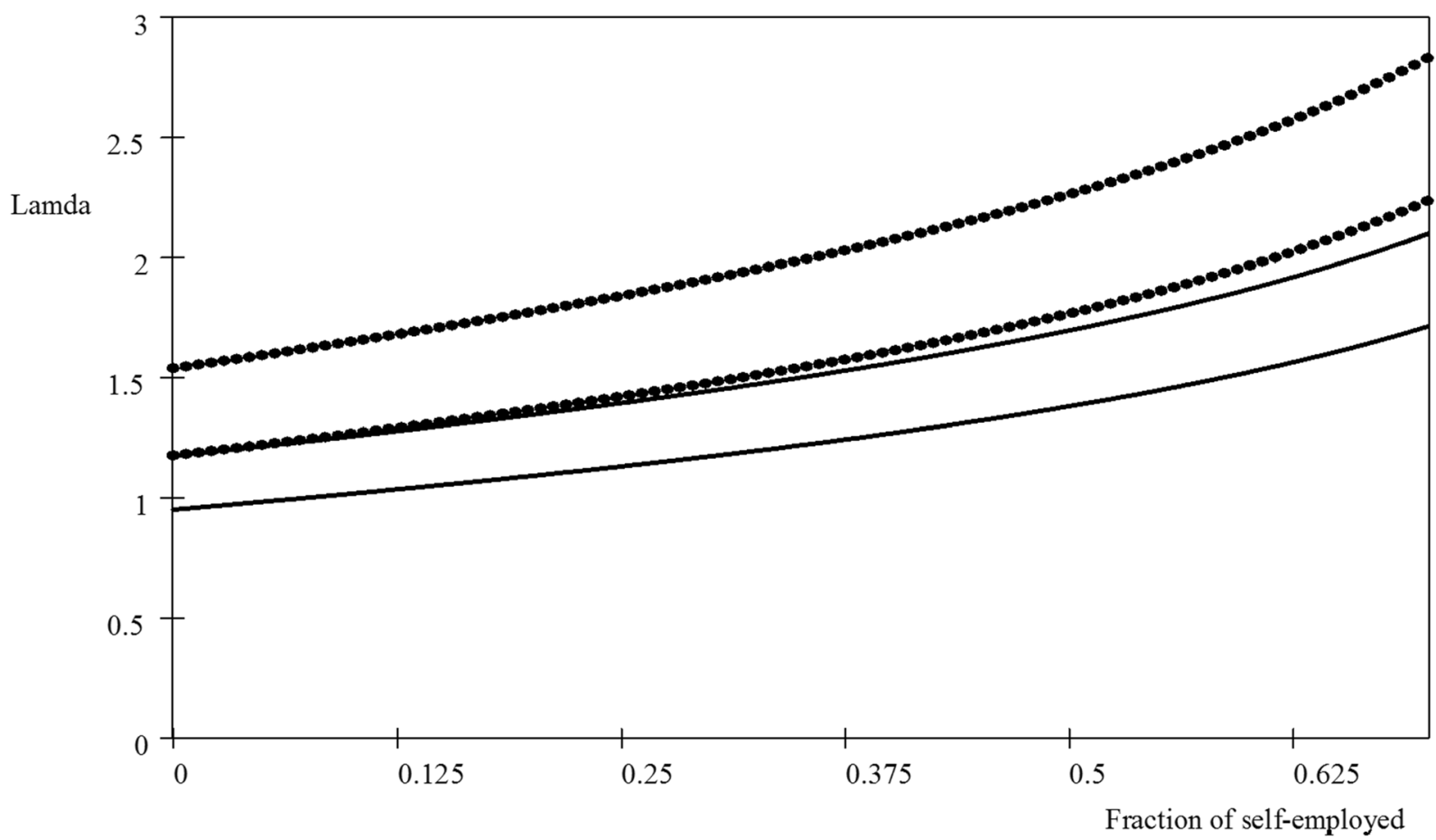

Fig. 2 Supply curves for self-employed electrical engineers (solid) and architects (dotted), where for each pair the lower curve refers to all self-employed and the upper curve to those hiring at least one person (1+). The $s$ and $\beta$ values are in accordance with Table 2

are correlated; see Lazear (2005). It would be an interesting avenue for future research to allow correlation between the skills and to test other distributions than the Fréchet distribution. Since the standard way to handle risk is to model utility as a nonlinear function of income, the use of a multiplicative adjustment factor is another simplification. A counter-argument is that experimental studies show that individuals tend to simplify their decisions when choosing between certain and uncertain outcomes; see Kahneman and Tversky (1979). Other shortcomings are that the multiplicative adjustment factor

Table 3 The ratio of computed to observed income percentiles in the year 2008 by education and occupational status

\begin{tabular}{|c|c|c|c|c|c|c|c|c|}
\hline \multirow[t]{3}{*}{ Percentiles } & \multicolumn{4}{|c|}{ Electrical engineers } & \multicolumn{4}{|c|}{ Architects } \\
\hline & \multicolumn{2}{|c|}{ Self-employed } & \multicolumn{2}{|c|}{ Wage employed $^{\mathrm{a}}$} & \multicolumn{2}{|c|}{ Self-employed } & \multicolumn{2}{|c|}{ Wage employed ${ }^{\mathrm{a}}$} \\
\hline & All & $1+$ & All & $1+$ & All & $1+$ & All & $1+$ \\
\hline 5 th & $-\mathrm{b}$ & 3.44 & 1.33 & 1.34 & $-b$ & 3.31 & 1.81 & 1.91 \\
\hline 25 th & 1.40 & 1.10 & 0.94 & 0.95 & 1.79 & 1.05 & 0.82 & 0.85 \\
\hline 50th & 0.95 & 0.97 & 0.91 & 0.92 & 0.88 & 0.95 & 0.82 & 0.84 \\
\hline 75th & 0.82 & 0.91 & 0.97 & 0.97 & 0.78 & 0.90 & 0.90 & 0.91 \\
\hline 95th & 0.70 & 0.84 & 1.12 & 1.12 & 0.76 & 0.87 & 1.21 & 1.17 \\
\hline
\end{tabular}

\footnotetext{
a The two columns under the heading "wage employed" differ somewhat because the parameters of the Fréchet distribution of incomes for wage employed have been calibrated separately when wage employed are compared with all self-employed and with self-employed 1+, respectively

${ }^{\mathrm{b}}$ Indicates that the observed income percentile is negative or equal to zero
} 
reflects the combined effect of risk handling and nonpecuniary benefits and that several of our theoretical derivations as well as empirical conclusions hinge on the assumption that the skills are Fréchetdistributed. Though the Fréchet assumption is compatible with empirical observations of the income distributions of self-employed and wage employed, we cannot rule out that this also holds for other distributions that make balanced skills sufficiently more common at low than at high skill levels. To test other conceivable distributions, however, will probably require heavy numerical calculations rather than our analytical derivations. Yet, we think it is warranted to further analyze the theoretical and empirical implications from applying different skill distributions in the specification of the Lazear model.

We think that our modification of Lazear's model can be extended in several directions. One improvement would be to allow correlation between the skills and another one to investigate the possibility of estimating the market value of entrepreneurial talent as a function of individual characteristics like age, gender, and their labor market region. Since the income returns to entrepreneurship and to wage employment should ensure that the supplies of entrepreneurs and specialists correspond to the demand, a more ambitious theoretical extension would be to develop a labor market equilibrium model that allows for simultaneous estimation of the market value of entrepreneurial talent, the utility adjustment factor, and the parameters of the skill profile distribution. ${ }^{20}$ It should be added that our specification of the skill distribution opens up for analyzing measures of cognitive abilities in a new way. The empirical tests of Lazear's model of the kind reported by Aldén et al. (2017) and Hartog et al. (2010), for instance, can be complemented with estimations that increase our knowledge of the skill distribution.

Acknowledgments We are very grateful to Vardan Hovsepyan for his able assistance with data handling, parameter computations, and figure production. We also thank Alfred Galichon for deriving the Fréchet correlation coefficient and two anonymous reviewers and Pontus Braunerhjelm, Börje Johansson, and Jörgen Weibull for valuable insights, comments, and suggestions.

Funding Information Open access funding provided by Royal Institute of Technology, Stockholm, Sweden.

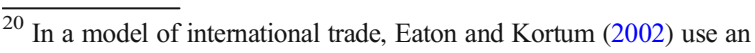
estimation approach of this kind.
}

\section{Appendix 1. Additional propositions, proofs, and parameter calibration}

Some basic properties of the Fréchet distribution

A continuous random variable $X>0$ is $\operatorname{Fréchet}(\beta, v)$ distributed with shape parameter $\beta>0$ and scale parameter $v>0$, if its c.d.f. is

$$
F(x)=e^{-(v / x)^{\beta}}, \quad x>0 .
$$

The expected value is $E[X]=v \cdot \Gamma(1-1 / \beta)$, provided that $\beta>1$, which is henceforth assumed, and the variance is $\operatorname{Var}[X]=v^{2} \cdot\left[\Gamma(1-2 / \beta)-\Gamma^{2}(1-1 / \beta)\right]$, provided that $\beta>2$. The expected value $E[X] \rightarrow v$ and the variance $\operatorname{Var}[X] \rightarrow 0$ as $\beta \rightarrow \infty$. If $X$ is Fréchet $(\beta, v)$, then $\tau X$ is Fréchet $(\beta, \tau)$ for any scalar $\tau>0$.

The following properties of the Fréchet distribution will be repeatedly used in the proofs. ${ }^{21}$ If $X_{1}$ and $X_{2}$ are statistically independent Fréchet $\left(\beta, v_{1}\right)$ and Fréchet $(\beta$, $v_{2}$ ), respectively, then

$p_{1}=\operatorname{Pr}\left[X_{1}>X_{2}\right]=\frac{v_{1}^{\beta}}{v_{1}^{\beta}+v_{2}^{\beta}}$,

and

$$
\begin{aligned}
\widehat{X} & =\max \left\{X_{1}, X_{2}\right\}, \widehat{X}_{1}=\left(X_{1} \mid X_{1}>X_{2}\right) \text { and } \widehat{X}_{2} \\
& =\left(X_{2} \mid X_{2}>X_{1}\right) \text { are all Fréchet }(\beta, \widehat{v}),
\end{aligned}
$$

with

$$
\widehat{v}=\left(v_{1}^{\beta}+v_{2}^{\beta}\right)^{1 / \beta} .
$$

\footnotetext{
$\overline{{ }^{21} \text { For proofs, }}$ see Corollary 3 in Mattsson et al. (2014), for example. Our present results can be extended to allow for positive statistical correlation by letting the joint c.d.f. of $X=\left(X_{1}, X_{2}\right)$ be $F\left(x_{1}, x_{2}\right)=e^{-\left[\left(v_{1} / x_{1}\right)^{\beta / \psi}+\left(v_{2} / x_{2}\right)^{\beta / \psi}\right]^{\psi}}$, for $\psi \in(0$, 1]. As shown by Galichon (2019), the correlation coefficient $\rho(\psi)$ exists for $\beta>2$ and is then $\rho(\psi)=$ $\frac{\Gamma^{2}(1-\psi / \beta) \cdot \Gamma(1-2 / \beta) / \Gamma(1-2 \psi / \beta)-\Gamma^{2}(1-1 / \beta)}{\Gamma(1-2 / \beta)-\Gamma^{2}(1-1 / \beta)}$. Specifically, $\rho(\psi) \rightarrow 1$ as $\psi \rightarrow 0$, and $\rho(1)=0$.
} 


\section{Proof of Proposition 2}

Proof The probability of a randomly drawn individual becoming a wage employee is $p_{\mathrm{W}}=\operatorname{Pr}\left[X_{1}>s \lambda X_{2}\right]+$ $\operatorname{Pr}\left[X_{2}>s \lambda X_{1}\right]$. Since $s \lambda X_{2}$ and $s \lambda X_{1}$ are both Fréchet $(\beta, s \lambda v)$ and $X_{1}$, and $X_{2}$ are statistically independent, it follows from Eq. (1) that

$p_{\mathrm{W}}=2 \frac{v^{\beta}}{(s \lambda v)^{\beta}+v^{\beta}}=\frac{2}{(s \lambda)^{\beta}+1}$,

and hence 22

$p_{E}=1-p_{W}=\frac{(s \lambda)^{\beta}-1}{(s \lambda)^{\beta}+1}$

Further claim of Proposition 3 and proof

In addition to the claims in Proposition 3, we also prove that the c.d.f. of entrepreneurial and wage employment incomes are, respectively,

$F_{Y_{E}}(x)=\frac{2(s \lambda)^{\beta} \cdot e^{-\left(\lambda^{\beta}+s^{-\beta}\right) \cdot(v / x)^{\beta}}-\left(1+(s \lambda)^{\beta}\right) \cdot e^{-2 \lambda^{\beta} \cdot(v / x)^{\beta}}}{(s \lambda)^{\beta}-1}, \quad x>0$,

and

$F_{Y_{W}}(x)=e^{-\left(1+(s \lambda)^{\beta}\right) \cdot(v / x)^{\beta}}, \quad x>0$.

Proof Note that since $X_{1}$ and $X_{2}$ are independent and identically distributed, all relationships are symmetric with respect to the two skills. Hence, it is no restriction to let the income of a wage employee be $Y_{\mathrm{W}}=\left(X_{1} \mid X_{1}>s \lambda X_{2}\right)$ which by (2) is Fréchet $(\beta, \widehat{v})$ with $\widehat{v}=\left(v^{\beta}+(s \lambda v)^{\beta}\right)^{1 / \beta}=\left(1+(s \lambda)^{\beta}\right)^{1 / \beta}$ $\cdot v$ from which its c.d.f. $F_{Y_{W}}$ and expected value $E\left[Y_{\mathrm{W}}\right]$ immediately follow.

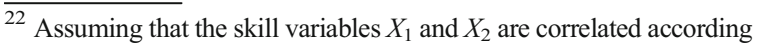
to the specification in the previous footnote, we have $P_{E}=$ $\left[(s \lambda)^{\beta / \psi}-1\right] /\left[(s \lambda)^{\beta / \psi}+1\right]$ for $\psi \in(0,1)$. Hence, the probability of entrepreneurship approaches one as the correlation coefficient approaches one, that is as $\psi \rightarrow 0$.
Similarly, it is no restriction to let the income of an entrepreneur be $Y_{\mathrm{E}}=\left(\lambda X_{1} \mid s \lambda X_{1}>X_{2}>X_{1}\right)$. Define the random variables $V=\left(\lambda X_{1} \mid s \lambda X_{1}>X_{2}\right)=\left(\lambda X_{1} \mid \lambda X_{1}>\right.$ $\left.s^{-1} X_{2}\right)$ and $R=\left(\lambda X_{1} \mid X_{1}>X_{2}\right)=\left(\lambda X_{1} \mid \lambda X_{1}>\lambda X_{2}\right)$, which by (2) are Fréchet $\left(\beta,\left(\lambda^{\beta}+s^{-\beta}\right)^{1 / \beta} \cdot v\right)$ and Fréchet $\left(\beta, 2^{1 / \beta} \lambda \cdot v\right)$, respectively. Evidently,

$$
\begin{aligned}
\operatorname{Pr}\left[s \lambda X_{1}>X_{2}\right] \cdot F_{V}(x)= & \operatorname{Pr}\left[s \lambda X_{1}>X_{2}>X_{1}\right] \\
& \cdot F_{Y_{E}}(x)+\operatorname{Pr}\left[X_{1}>X_{2}\right] \\
& \cdot F_{R}(x),
\end{aligned}
$$

where $F_{V}, F_{Y_{E}}$, and $F_{R}$ are the c.d.f.s of $V, Y_{E}$, and $R$, respectively. By (1)

$\operatorname{Pr}\left[s \lambda X_{1}>X_{2}\right]=\frac{(s \lambda v)^{\beta}}{v^{\beta}+(s \lambda v)^{\beta}}=\frac{(s \lambda)^{\beta}}{1+(s \lambda)^{\beta}}$,

$\operatorname{Pr}\left[X_{1}>X_{2}\right]=\frac{1}{2}$,

and by (3)

$\operatorname{Pr}\left[s \lambda X_{1}>X_{2}>X_{1}\right]=\frac{1}{2} P_{E}=\frac{1}{2} \cdot \frac{(s \lambda)^{\beta}-1}{(s \lambda)^{\beta}+1}$.

Hence

$$
\begin{aligned}
F_{Y_{E}}(x) & =\frac{\frac{(s \lambda)^{\beta}}{1+(s \lambda)^{\beta}} \cdot F_{V}(x)-\frac{1}{2} \cdot F_{R}(x)}{\frac{1}{2} \cdot \frac{(s \lambda)^{\beta}-1}{(s \lambda)^{\beta}+1}} \\
& =\frac{2(s \lambda)^{\beta} \cdot F_{V}(x)-\left(1+(s \lambda)^{\beta}\right) \cdot F_{R}(x)}{(s \lambda)^{\beta}-1}
\end{aligned}
$$

with $F_{V}(x)=e^{-\left(\lambda^{\beta}+s^{-\beta}\right) \cdot(v / x)^{\beta}}$ and $F_{R}(x)=e^{-2 \lambda^{\beta} \cdot(v / x)^{\beta}}$.

From (4) it follows that

$E\left[Y_{\mathrm{E}}\right]=\frac{2(s \lambda)^{\beta} \cdot \mathrm{E}[V]-\left(1+(s \lambda)^{\beta}\right) \cdot \mathrm{E}[R]}{(s \lambda)^{\beta}-1}$

with $\mathrm{E}[V]=s^{-1}\left(1+(s \lambda)^{\beta}\right)^{1 / \beta} \cdot v \cdot \Gamma(1-1 / \beta)$ and $E[R]=$ $2^{1 / \beta} \lambda \cdot v \cdot \Gamma(1-1 / \beta)$. 


\section{Proof of Proposition 4}

Proof Remember that $s \cdot \lambda>1$ by assumption. The statement of the proposition, rewritten as $E\left[Y_{\mathrm{W}}\right]>$ $s \cdot \mathrm{E}\left[Y_{E}\right]$, follows if the equality

$E\left[Y_{\mathrm{W}}\right]=\alpha \cdot s \cdot \mathrm{E}\left[Y_{E}\right]+(1-\alpha) \cdot Q$

is satisfied for some $\alpha \in(0,1)$ and $Q>E\left[Y_{\mathrm{W}}\right]$, since $E\left[Y_{\mathrm{W}}\right] \leq s \cdot E\left[Y_{\mathrm{E}}\right]$ would then lead to a contradiction. Given the expressions for $E\left[Y_{\mathrm{W}}\right]$ and $E\left[Y_{\mathrm{E}}\right]$ from Proposition 3, the equality (5) is easily verified for $\alpha=$ $\frac{(s \lambda)^{\beta}-1}{2(s \lambda)^{\beta}} \in(0,1)$ and $Q=2^{1 / \beta} s \cdot \lambda \cdot v \cdot \Gamma(1-1 / \beta)>E\left[Y_{\mathrm{W}}\right]$.

\section{Proof of Proposition 5}

Proof By definition, $b=1-E\left[Z_{\mathrm{E}}\right] / E\left[Y_{\mathrm{W}}\right]$. Let $\varphi=(s \lambda)^{\beta}$. By Proposition 3 and the Proof of Proposition 6 below, we have $b=1-\frac{2^{1 / \beta}(1+\varphi)^{1-1 / \beta}-2}{\varphi-1}$, and, since $\varphi=\left(1+p_{E}\right) /\left(1-p_{E}\right)$ by Proposition $2, b$ as a function of $p_{\mathrm{E}}$ becomes

$b\left(p_{\mathrm{E}}\right)=\frac{1-\left(1-p_{\mathrm{E}}\right)^{1 / \beta}}{p_{\mathrm{E}}}$.

Evidently $b=1$ for $p_{E}=1$ and by l'Hôpital's rule $b$ goes to $1 / \beta$ as $p_{E}$ decreases to 0 . We want to show that $b$ as a function of $p_{\mathrm{E}}$ is strictly increasing in the interval $(0,1) .{ }^{23}$ It is somewhat simpler to prove the equivalent statement that $b$ as a function of $p_{\mathrm{W}}=1-p_{\mathrm{E}}$ is strictly decreasing in the interval $(0,1)$. Then

$b\left(p_{\mathrm{W}}\right)=\frac{1-p_{\mathrm{W}}^{1 / \beta}}{1-p_{\mathrm{W}}}$

with the derivative

$b^{\prime}\left(p_{\mathrm{W}}\right)=\frac{(1 / \beta) p_{\mathrm{W}}^{1 / \beta-1}+(1-1 / \beta) p_{\mathrm{W}}^{1 / \beta}-1}{\left(1-p_{\mathrm{W}}\right)^{2}}$.

Consider the numerator

$c\left(p_{\mathrm{W}}\right)=(1 / \beta) p_{\mathrm{W}}^{1 / \beta-1}+(1-1 / \beta) p_{\mathrm{W}}^{1 / \beta}-1$

and note that $c(1)=0$. Hence, $b^{\prime}\left(p_{W}\right)<0$ for all $p_{\mathrm{W}} \in$ $(0,1)$ if $c^{\prime}\left(p_{\mathrm{w}}\right)>0$ for all $p_{\mathrm{W}} \in(0,1)$. Recalling that $\beta>$ 1 , this is indeed the case since

\footnotetext{
${ }^{23}$ The authors thank Jörgen Weibull for suggesting this proof.
}

$c^{\prime}\left(p_{\mathrm{W}}\right)=-\frac{1}{\beta}\left(\frac{1}{\beta}-1\right) \cdot\left(1-p_{\mathrm{W}}\right) p_{\mathrm{W}}^{1 / \beta-2}>0$.

Finally, it is easily verified that $b$ is strictly decreasing in $\beta>1$.

Formulation and proof of Proposition 6

Proposition 6 Consider Lazear's model with the same assumptions as in Proposition 2.

The counterfactual income returns to entrepreneurship are then

$\mu_{\mathrm{E}}=\frac{\mathrm{E}\left[Y_{\mathrm{E}}\right]}{\mathrm{E}\left[\mathrm{Z}_{\mathrm{E}}\right]}=\frac{2^{1-1 / \beta} s^{\beta-1} \lambda^{\beta}-\lambda \cdot\left(1+(s \lambda)^{\beta}\right)^{1-1 / \beta}}{\left(1+(s \lambda)^{\beta}\right)^{1-1 / \beta}-2^{1-1 / \beta}}$,

and the counterfactual income returns to wage employment are

$\mu_{\mathrm{W}}=\frac{E\left[Y_{\mathrm{W}}\right]}{E\left[\mathrm{Z}_{\mathrm{W}}\right]}=\frac{1}{\lambda \cdot\left(1+(s \lambda)^{\beta}\right)^{1-1 / \beta}-s^{\beta-1} \lambda^{\beta}}$.

Proof Since $X_{1}$ and $X_{2}$ are independent and identically distributed, it is no restriction to let $Z_{E}=\left(X_{2} \mid s \lambda X_{1}>X_{2}>X_{1}\right)$. Define the random variables $V=\left(X_{2} \mid X_{2}>s \lambda X_{1}\right)$ and $R=\left(X_{2} \mid X_{2}>X_{1}\right)$, which by (2) are Fréchet $\left(\beta,\left(1+(s \lambda)^{\beta}\right)^{1 / \beta} \cdot v\right)$ and Fréchet $\left(\beta, 2^{1 / \beta} \cdot v\right)$, respectively, and hence $E[V]=\left(1+(s \lambda)^{\beta}\right)^{1 / \beta} \cdot v \cdot \Gamma(1-1 / \beta)$ and $E[R]=2^{1 / \beta}$. $v \cdot \Gamma(1-1 / \beta)$, respectively. Evidently,

$$
\begin{aligned}
\operatorname{Pr}\left[X_{2}>X_{1}\right] \cdot E[R]= & \operatorname{Pr}\left[X_{2}>s \lambda X_{1}\right] \cdot E[V] \\
& +\operatorname{Pr}\left[s \lambda X_{1}>X_{2}>X_{1}\right] \\
& \cdot E\left[Z_{\mathrm{E}}\right] .
\end{aligned}
$$

By (1)

$\operatorname{Pr}\left[X_{2}>X_{1}\right]=\frac{1}{2}$,

$\operatorname{Pr}\left[X_{2}>s \lambda X_{1}\right]=\frac{1}{1+(s \lambda)^{\beta}}$,

and by (3)

$\operatorname{Pr}\left[s \lambda X_{1}>X_{2}>X_{1}\right]=\frac{1}{2} P_{\mathrm{E}}=\frac{1}{2} \cdot \frac{(s \lambda)^{\beta}-1}{(s \lambda)^{\beta}+1}$. 
Hence

$E\left[Z_{\mathrm{E}}\right]=\frac{2^{1 / \beta}\left(1+(s \lambda)^{\beta}\right)-2\left(1+(s \lambda)^{\beta}\right)^{1 / \beta}}{(s \lambda)^{\beta}-1} \cdot v \cdot \Gamma(1-1 / \beta)$,

which together with the expression for $E\left[Y_{\mathrm{E}}\right]$ from Proposition 3 establishes the required expression for $\mu_{\mathrm{E}}$.

Similarly, it is no restriction to let $Z_{\mathrm{W}}=\left(\lambda X_{1}\left|X_{2}\right\rangle\right.$ $\left.s \lambda X_{1}\right)$. Define the random variable $V=\left(\lambda X_{1} \mid s \lambda X_{1}>\right.$ $\left.X_{2}\right)=\left(\lambda X_{1} \mid \lambda X_{1}>s^{-1} X_{2}\right)$, which by (2) is Fréchet $\left(\beta,\left(\lambda^{\beta}+s^{-\beta}\right)^{1 / \beta} \cdot v\right)$, and hence $E[V]=\left(\lambda^{\beta}+\right.$ $\left.s^{-\beta}\right)^{1 / \beta} \cdot v \cdot \Gamma(1-1 / \beta)$. Evidently,

$$
\begin{aligned}
E\left[\lambda X_{1}\right]= & \operatorname{Pr}\left[X_{2}>s \lambda X_{1}\right] \cdot E\left[Z_{\mathrm{W}}\right]+\operatorname{Pr}\left[s \lambda X_{1}>X_{2}\right] \\
& \cdot E[V] .
\end{aligned}
$$

By (1)

$\operatorname{Pr}\left[X_{2}>s \lambda X_{1}\right]=\frac{1}{1+(s \lambda)^{\beta}}$, and

$\operatorname{Pr}\left[s \lambda X_{1}>X_{2}\right]=\frac{(s \lambda)^{\beta}}{1+(s \lambda)^{\beta}}$.

Since $E\left[\lambda X_{1}\right]=\lambda \cdot v \cdot \Gamma(1-1 / \beta)$ we get

$$
\begin{aligned}
E\left[Z_{\mathrm{W}}\right]= & \left(\lambda \cdot\left(1+(s \lambda)^{\beta}\right)-(s \lambda)^{\beta} \cdot\left(\lambda^{\beta}+s^{-\beta}\right)^{1 / \beta}\right) \cdot v \\
& \cdot \Gamma(1-1 / \beta),
\end{aligned}
$$

which together with the expression for $E\left[Y_{\mathrm{W}}\right]$ from Proposition 3 establishes the required expression for $\mu_{\mathrm{W}}$.

Applied procedure for parameter calibration

To apply the modified Lazear model as specified in Proposition 2, four parameters need to be calibrated against empirical data: $s, \lambda, \beta$, and $v$. It is assumed that data are available for the relative frequency of entrepreneurs (self-employed) $\bar{p}_{\mathrm{E}}$ as well as for the $p$ percentiles of the income distributions $\bar{Y}_{\mathrm{p}}^{\mathrm{E}}$ and $\bar{Y}_{\mathrm{p}}^{\mathrm{W}}, p \in\{0.05,0.25$, $0.5,0.75,0.95\}$, and the average incomes $\bar{Y}_{\mathrm{E}}$ and $\bar{Y}_{\mathrm{W}}$ of entrepreneurs and wage employees, respectively. We will use $\bar{p}_{\mathrm{E}}$ as our observation for $p_{\mathrm{E}}$, and $\bar{Y}_{\mathrm{E}}$ and $\bar{Y}_{\mathrm{W}}$ as our observations for $E\left[Y_{\mathrm{E}}\right]$ and $E\left[Y_{\mathrm{W}}\right]$, respectively.

Let $\varphi \equiv(s \lambda)^{\beta}$. By Proposition 2

$\varphi=\frac{1+\bar{p}_{\mathrm{E}}}{1-\bar{p}_{\mathrm{E}}}$ and by Proposition 3

$\frac{\bar{Y}_{\mathrm{E}}}{\bar{Y}_{\mathrm{W}}}=\frac{1}{S} \cdot \frac{2 \varphi-2^{1 / \beta} \varphi^{1 / \beta}(1+\varphi)^{1-1 / \beta}}{\varphi-1}$.

The last equation can be solved for $\beta$ as a function of $s \in\left(0, \bar{Y}_{W} / \bar{Y}_{E}\right)$

$\beta(s)=\frac{\ln (2 \varphi)-\ln (1+\varphi)}{\ln \left[2 \varphi-s \cdot\left(\bar{Y}_{E} / \bar{Y}_{W}\right) \cdot(\varphi-1)\right]-\ln (1+\varphi)}$,

and hence $\lambda$ as a function of $s$ is

$\lambda(s)=\frac{\varphi^{1 / \beta(s)}}{s}=\frac{1}{s} \cdot\left(\frac{1+p_{E}}{1-p_{E}}\right)^{1 / \beta(s)}$

and by Proposition 3, $v$ as a function of $s$ is

$v(s)=\frac{\bar{Y}_{W}}{(1+\varphi)^{1 / \beta(s)} \cdot \Gamma(1-1 / \beta(s))}$.

Next, the $p$ percentiles $Y_{\mathrm{p}}^{\mathrm{E}}(s)$ and $Y_{\mathrm{p}}^{W}(s)$ of the income distributions $F_{Y_{E}}$ and $F_{Y_{W}}$, as specified in the proof of Proposition 3 in Appendix 1, are derived from the equations $F_{Y_{E}}\left(Y_{p}^{E}(s)\right)=p$ and $F_{Y_{W}}\left(Y_{p}^{W}(s)\right)=p$, given the parameters $\beta(s), \lambda(s), v(s)$, and $s$, for $p \in\{0.05,0.25,0.5,0.75,0.95\}$. The equations for the percentiles for wage employees can be solved analytically

$Y_{\mathrm{p}}^{\mathrm{W}}(s)=v(s)\left(\frac{1+\varphi}{-\ln p}\right)^{1 / \beta(s)}$,

while the equations for the percentiles for entrepreneurs $Y_{p}^{E}(s)$ have to be solved numerically.

Finally, $s$ is determined so as to minimize the sum of the quadratic deviations between the $p$ percentiles of the observed and computed income distributions of entrepreneurs and wage employees ${ }^{24}$ :

$\min _{s \in\left(0, \bar{Y}_{W} / \bar{Y}_{E}\right.} \sum_{p \in\{0.05,0.25,0.5,0.75,0.95\}}\left[\left(Y_{p}^{E}(s)-\bar{Y}_{p}^{E}\right)^{2}+\left(Y_{p}^{W}(s)-\bar{Y}_{p}^{W}\right)^{2}\right]$.

\footnotetext{
${ }^{24}$ The calibrated parameters remind of regression estimates. The sum of the squared differences between observed and computed income percentiles is minimized while keeping the average of the computed incomes equal to the average of the observed incomes.
} 


\section{Appendix 2. Additional data}

Table 4 Number of individuals $n$, average income $\bar{Y}$, and median income $m$ by education, year, and occupational status. Annual income in thousand SEK

\begin{tabular}{|c|c|c|c|c|c|c|c|}
\hline \multirow[t]{2}{*}{ Year } & \multirow[t]{2}{*}{ Occupational status } & \multicolumn{3}{|c|}{ Electrical engineers } & \multicolumn{3}{|c|}{ Architects } \\
\hline & & $n$ & $\bar{Y}$ & $m$ & $n$ & $\bar{Y}$ & $m$ \\
\hline \multirow[t]{3}{*}{2004} & Wage employed & 11,210 & 518 & 479 & 3223 & 330 & 329 \\
\hline & Self-employed: all & 1000 & 340 & 309 & 1245 & 257 & 252 \\
\hline & Self-employed: $1+$ & 454 & 420 & 391 & 564 & 341 & 334 \\
\hline \multirow[t]{3}{*}{2005} & Wage employed & 11,325 & 528 & 487 & 3322 & 337 & 337 \\
\hline & Self-employed: all & 1066 & 349 & 326 & 1246 & 272 & 273 \\
\hline & Self-employed: $1+$ & 488 & 431 & 405 & 561 & 367 & 353 \\
\hline \multirow[t]{3}{*}{2006} & Wage employed & 11,669 & 539 & 496 & 3416 & 355 & 346 \\
\hline & Self-employed: all & 1091 & 364 & 344 & 1284 & 285 & 286 \\
\hline & Self-employed: $1+$ & 470 & 422 & 411 & 584 & 372 & 362 \\
\hline \multirow[t]{3}{*}{2007} & Wage employed & 11,909 & 557 & 508 & 3599 & 364 & 356 \\
\hline & Self-employed: all & 1122 & 358 & 340 & 1242 & 299 & 288 \\
\hline & Self-employed: $1+$ & 476 & 443 & 432 & 569 & 403 & 370 \\
\hline \multirow[t]{3}{*}{2008} & Wage employed & 11,877 & 576 & 524 & 3657 & 377 & 370 \\
\hline & Self-employed: all & 1211 & 368 & 361 & 1287 & 291 & 304 \\
\hline & Self-employed: $1+$ & 533 & 454 & 438 & 603 & 385 & 377 \\
\hline
\end{tabular}

Table 5 Observed income percentiles in the year 2008 by education and occupational status

\begin{tabular}{|c|c|c|c|c|c|c|}
\hline \multirow[t]{3}{*}{ Percentiles } & \multicolumn{3}{|c|}{ Electrical engineers } & \multicolumn{3}{|c|}{ Architects } \\
\hline & \multicolumn{2}{|c|}{ Self-employed } & \multirow[t]{2}{*}{ Wage employed } & \multicolumn{2}{|c|}{ Self-employed } & \multirow[t]{2}{*}{ Wage employed } \\
\hline & All & $1+$ & & All & $1+$ & \\
\hline 5 th & 0 & 87 & 219 & 0 & 75 & 97 \\
\hline 25 th & 209 & 329 & 401 & 126 & 288 & 287 \\
\hline 50 th & 361 & 438 & 524 & 304 & 377 & 370 \\
\hline 75th & 505 & 563 & 664 & 424 & 483 & 465 \\
\hline 95th & 822 & 845 & 1028 & 625 & 707 & 659 \\
\hline 99th & 1091 & 1106 & 1776 & 981 & 1021 & 914 \\
\hline
\end{tabular}


Open Access This article is licensed under a Creative Commons Attribution 4.0 International License, which permits use, sharing, adaptation, distribution and reproduction in any medium or format, as long as you give appropriate credit to the original author(s) and the source, provide a link to the Creative Commons licence, and indicate if changes were made. The images or other third party material in this article are included in the article's Creative Commons licence, unless indicated otherwise in a credit line to the material. If material is not included in the article's Creative Commons licence and your intended use is not permitted by statutory regulation or exceeds the permitted use, you will need to obtain permission directly from the copyright holder. To view a copy of this licence, visit http://creativecommons.org/licenses/by/4.0/.

\section{References}

Aldén, L., Hammarstedt, M., \& Neuman, E. (2017). All about balance? A test of the jack-of-all-trades theory using military enlistment data. Labour Economics, 49, 1-13. https://doi. org/10.1016/j.labeco.2017.09.001.

Åstebro, T. (2012). The returns to entrepreneurship. In D. Cumming (Ed.), The Oxford Handbook of Entrepreneurial Finance (pp. 45-108). Oxford: Oxford University Press. https://doi.org/10.1093/oxfordhb/9780195391244.013.0003.

Åstebro, T., \& Chen, J. (2014). The entrepreneurial earnings puzzle: Mismeasurement or real? Journal of Business Venturing, 29, 88-105. https://doi.org/10.1016/j.jbusvent.2013.04.003.

Åstebro, T., \& Thompson, P. (2011). Entrepreneurs, jacks of all trades or hobos? Research Policy, 40, 637-649. https://doi. org/10.1016/j.respol.2011.01.010.

Åstebro, T., Chen, J., \& Thompson, P. (2011). Stars and misfits: Self-employment and labor market frictions. Management Science, 57, 1999-2017. https://doi.org/10.1287 /mnsc. 1110.1400 .

Benz, M. (2009). Entrepreneurship as a non-profit-seeking activity. The International Entrepreneurship and Management Journal, 5, 23-44. https://doi.org/10.1007/s11365-0060031-y.

Berglann, H., Moen, E. R., Røed, K., \& Skogstrøm, J. F. (2011). Entrepreneurship: Origins and returns. Labour Economics, 18, 180-193. https://doi.org/10.1016/j.labeco.2010.10.002.

Block, J., Sandner, P., \& Spiegel, F. (2015). How do risk attitudes differ within the group of entrepreneurs? The role of motivation and procedural utility. Journal of Small Business Management, 53(1), 183-206. https://doi.org/10.1111 jjsbm. 12060.

Brown, S., Dietrich, M., Ortiz-Nunez, A., \& Taylor, K. (2011). Self-employment and attitudes towards risk: Timing and unobserved heterogeneity. Journal of Economic Psychology, 32, 425-433. https://doi.org/10.1016/j. joep.2011.02.015.

Bublitz, E., \& Noseleit, F. (2014). The skill balancing act: When does broad expertise pay off? Small Business Economics, 42, 17-32, Special Issue: INBAM 2012. https://doi.org/10.1007 /s11187-013-9474-z.
Cho, I., \& Orazem, P. (2014). Are nonprofit entrepreneurs also jacks-of-all-trades? IZA Journal of Labor Economics, 3, 4. https://doi.org/10.1186/2193-8997-3-4.

Dvouletý, O., Procházka, D. A., \& Starnawska, M. (2019). Who earns more: Job creators, solo-entrepreneurs or employees? Empirical evidence from Visegrad countries. International Journal of Entrepreneurship and Small Business, 1(1), 1-14. https://doi.org/10.1504/IJESB.2019.10020600.

Eaton, J., \& Kortum, S. (2002). Technology, geography, and trade. Econometrica, 70, 1741-1779. https://doi.org/10.1111 /1468-0262.00352.

Ekelund, J., Johansson, E., Järvelin, M.-R., \& Lichtermann, D. (2005). Self-employment and risk aversion - Evidence from psychological test data. Labour Economics, 12, 649-659. https://doi.org/10.1016/j.labeco.2004.02.009.

Frey, B., Benz, M., \& Stutzer, A. (2004). Introducing procedural utility: Not only what, but also how matters. Journal of Institutional and Theoretical Economics, 160, 377-401 https://www.jstor.org/stable/40752468.

Galichon, A. (2019). On the representation of the nested logit model. https://arxiv.org/pdf/1907.08766.

Hamilton, B. H. (2000). Does entrepreneurship pay? An empirical analysis of the returns to self-employment. Journal of Political Economy, 108, 604-631. https://doi.org/10.1086 /262131.

Hårsman, B., Mattsson, L.-G., \& Hovsepyan, V. (2018). The income return to entrepreneurship - Theoretical model and outcomes for Swedish regions. The Annals of Regional Science, 61, 479-498. https://doi.org/10.1007/s00168-0180883-4.

Hartog, J., van Praag, M., \& van der Sluis, J. (2010). If you are so smart, why aren't you an entrepreneur? Returns to cognitive and social ability: Entrepreneurs versus employees. Journal of Economics \& Management Strategy, 19, 947-989. https://doi.org/10.1111/j.1530-9134.2010.00274.x.

Hsieh, C., Parker, S. C., \& van Praag, C. M. (2017). Risk, balanced skills and entrepreneurship. Small Business Economics, 48, 287-302. https://doi.org/10.1007/s11187-016-9785-y.

Hvide, H. K., \& Panos, G. A. (2014). Risk tolerance and entrepreneurship. Journal of Financial Economics, 111, 200-223. https://doi.org/10.1016/j.jfineco.2013.06.001.

Hyytinen, A., Ilmakunnas, P., \& Toivanen, O. (2013). The returnto-entrepreneurship puzzle. Labour Economics, 20, 57-67. https://doi.org/10.1016/j.labeco.2012.11.002.

Jovanovic, B. (2019). The entrepreneurship premium. Small Business Economics. https://doi.org/10.1007/s11187-01900234-w.

Kahneman, D., \& Tversky, A. (1979). Prospect theory: An analysis of decision under risk. Econometrica, 47(2), 263-292. https://doi.org/10.1142/9789814417358_0006.

Kotz, S., \& Nadarajah, S. (2000). Extreme value distributions: Theory and applications. London: Imperial College Press. https://doi.org/10.1142/p191.

Krieger, A., Block, J., \& Stuetzer, M. (2018). Skill variety in entrepreneurship: A literature review and research directions. International Review of Entrepreneurship, 16, 29-62 https://mpra.ub.uni-muenchen.de/88389/.

Lazear, E. P. (2002). Entrepreneurship, Working Paper 9109 , NBER Working Paper Series. Cambridge: National Bureau of Economic Research. https://doi.org/10.3386/w9109. 
Lazear, E. P. (2004). Balanced skills and entrepreneurship. American Economic Review, 94, 208-211. https://doi. org/10.1257/0002828041301425.

Lazear, E. P. (2005). Entrepreneurship. Journal of Labor Economics, 23, 649-680. https://doi.org/10.1086/491605.

Lechman, D. (2015). Can working conditions explain the returnto-entrepreneurship puzzle? Journal for Labour Market Research, 48, 271-286. https://doi.org/10.1007/s12651015-0172-y.

Levine, R., \& Rubinstein, Y. (2016). Smart and illicit: Who becomes an entrepreneur and do they earn more? The Quarterly Journal of Economics, 132(2), 963-1018. https://doi.org/10.1093/qje/qjw044.

Mattsson, L.-G., Weibull, J. W., \& Lindberg, P. O. (2014). Extreme values, invariance and choice probabilities. Transportation Research Part B, 59, 81-95. https://doi. org/10.1016/j.trb.2013.10.014.

Parker, S. C. (2018). The economics of entrepreneurship (2nd ed.). Cambridge: Cambridge University Press.
Tegtmeier, S., Kurczewska, A., \& Halberstadt, J. (2016). Are women graduates jacquelines-of-all-trades? Challenging Lazear's view on entrepreneurship. Small Business Economics, 47, 77-94. https://doi.org/10.1007/s11187-0169727-8.

Wagner, J. (2003). Testing Lazear's jack-of-all-trades view of entrepreneurship with German micro-data. Applied Economics Letters, 10, 687-689. https://doi.org/10.1080 $/ 1350485032000133273$.

Wagner, J. (2006). Are nascent entrepreneurs 'jacks-of-all-trades'? A test of Lazear's theory of entrepreneurship with German data. Applied Economics, 38, 2415-2419. https://doi. org/10.1080/00036840500427783.

Publisher's note Springer Nature remains neutral with regard to jurisdictional claims in published maps and institutional affiliations. 